\title{
Early snowmelt reduces aphid abundance (Aphis asclepiadis) by creating water-stressed host plants (Ligusticum porteri) and altering interactions with ants
}

\author{
Emily Mooney ${ }^{1,2}$ (]) Maria Mullins ${ }^{1,2} \cdot$ James Den Uyl ${ }^{1,2} \cdot$ Samantha Trail ${ }^{2,3} \cdot$ Phuong Nguyen $^{4} \cdot$ Janel Owens $^{4}$. \\ Elsa Godtfredsen ${ }^{5}$. Shane Heschel ${ }^{5}$
}

Received: 25 January 2020 / Accepted: 3 November 2020 / Published online: 16 November 2020

(c) The Author(s) 2020

\begin{abstract}
Declining snow cover is reshaping ecological communities. Early loss of snow cover initiates changes in key interactions that mediate herbivore abundance, i.e., top-down and bottom-up effects. In this study, we used a field experiment to test the effects of host plant water stress and phenology on the multitrophic interactions that determine aphid abundance. The aphid, Aphis asclepiadis, in our study system colonizes the flowering stalks of the host plant Ligusticum porteri and relies on a protection mutualism with ants. We added snow and water to replicate host plants and tested for a variety of phenological and physiological responses to these treatments. Relative to host plants in ambient conditions, both water and snow addition reduced key signals of water stress (senescence and abscisic acid levels) and increased seed set. While aphid colonies were generally larger with reduced host plant water stress, the ant-aphid mutualism interacted with plant quality in complex ways. Without ant tending, we did not detect differences in aphid colony growth with host plant treatment. When tended by ants, aphid colony growth was greatest on host plants with snow addition. Host plant quality also altered the benefits exchanged in this mutualism. Ant-tended colonies hosted by plants with snow addition produced honeydew enriched in trehalose, which may have decreased both ant and natural enemy abundance. Our results suggest that early loss of snow reduces aphid abundance by creating low-quality, water-stressed host plants, and this effect may be exacerbated by natural enemies and the costs of ant attendance.
\end{abstract}

Keywords Snow cover $\cdot$ Ant-aphid mutualism $\cdot$ Climate change $\cdot$ Water stress

Handling Editor: Heikki Hokkanen.

Electronic supplementary material The online version of this article (https://doi.org/10.1007/s11829-020-09793-2) contains supplementary material, which is available to authorized users.

Emily Mooney

emooney@uccs.edu

1 Rocky Mountain Biological Laboratory, PO Box 519, Crested Butte, CO 81224, USA

2 Department of Biology, University of Colorado Colorado Springs, 1420 Austin Bluffs Parkway, Colorado Springs, CO 80918, USA

3 Pikes Peak School of Expeditionary Learning, 11925 Antlers Ridge Dr, Peyton, CO 80831, USA

4 Department of Chemistry and Biochemistry, University of Colorado Colorado Springs, 1420 Austin Bluffs Parkway, Colorado Springs, CO 80918, USA

5 Colorado College, 14 E Cache La Poudre St, Colorado Springs, CO 80903, USA

\section{Introduction}

The duration and amount of snow cover is declining in a variety of ecosystems due to climate change, and these declines are reshaping biological communities (Niittynen et al. 2018). Changing snow cover alters the bottom-up and top-down effects that govern herbivore abundance (Penczykowski et al. 2017). From the bottom-up perspective, snow cover loss reduces soil moisture, initiating water stress in plants (Harpold 2016), and water stress often determines the quality of host plants to herbivores (Jamieson et al. 2012). While moderate water stress can sometimes improve quality (Hale et al. 2003; Tariq et al. 2012), cross-talk between drought and defense hormonal pathways may make waterstressed plants more resistant to herbivores (Guo et al. 2016; Nguyen et al. 2016). In addition to initiating water stress, early snow cover loss advances phenology. This can desynchronize the stages at which plants, herbivores and natural 
enemies interact, which may either decrease and increase herbivore abundance (Fuchs et al. 2017; Renner and Zohner 2018; Kharouba and Wolkovich 2020). Overall, such mismatches have largely been explored in the context of elevated temperatures rather than snow cover.

In addition to top-down and bottom-up processes, mutualisms also mediate the abundance of many insect herbivores. For example, approximately $40 \%$ of aphid species are tended by ants (Ness et al. 2010), and ant tending can almost entirely regulate the abundance and distribution of some aphid species on their host plants (Müller and Godfray 1999). Ants protect aphids from predators, and aphids supply ants with honeydew, which is a high (90-95\%) carbohydrate, low amino acid excretion derived from host plant phloem sap (Stadler and Dixon 2005). As described in a recent review (Blanchard et al. 2019), climate change can alter many aspects of this mutualism: population dynamics, behavioral interactions, honeydew production and chemical communication. These past studies have focused exclusively on the effects of elevated temperatures and carbon dioxide concentrations (Blanchard et al. 2019). Snow cover declines could similarly alter the ant-aphid mutualism. Host plant water stress reduces aphid abundance (Banfield-Zanin and Leather 2015), and these small colonies may be unlikely to recruit ant mutualists (Breton and Addicott 1992a; Sakata 1994, 1999). Water stress can increase the concentration of amino acids in phloem sap (Hale et al. 2003), possibly increasing attractiveness of resulting aphid honeydew to ant mutualists (Pringle et al. 2014). Any effects of snow cover decline on the ant-aphid mutualism remain unexplored.

In this study, we used a field experiment to examine the effects of snow cover on aphid abundance. Our study system consists of the aphid herbivore, Aphis asclepiadis, which colonizes the flowering stalks of the subalpine host plant, Ligusticum porteri (Fig. 1a). Colonies of this aphid are dependent upon the protection mutualism with ants. In a previous experimental study in our system, A. asclepiadis colonies without ant protection declined to extinction (Mooney et al. 2016). Year-to-year variation in colony abundance on host plants is most closely associated with the timing of snowmelt (Fig. 1b: Robinson et al. 2017). An 8-year observational study shows that $A$. asclepiadis colonizes very few (1\%) of host plants in early snowmelt years and many more host plants (60\%) are colonized in late snowmelt years (Mooney et al. 2019). We hypothesized that early snowmelt reduces aphid abundance to this extent through multiple mechanisms (Fig. 2). Firstly, we predicted that early loss of snow cover will both induce water stress and advanced phenology of host plants, and their combined effects would reduce the quality of $L$. porteri as host for A. asclepiadis aphids. Snowmelt timing is the chief determinant of year-toyear variation in $L$. porteri flowering phenology (Iler et al. 2013). However, snowmelt timing does not similarly predict when host plants are colonized by A. asclepiadis (Mooney
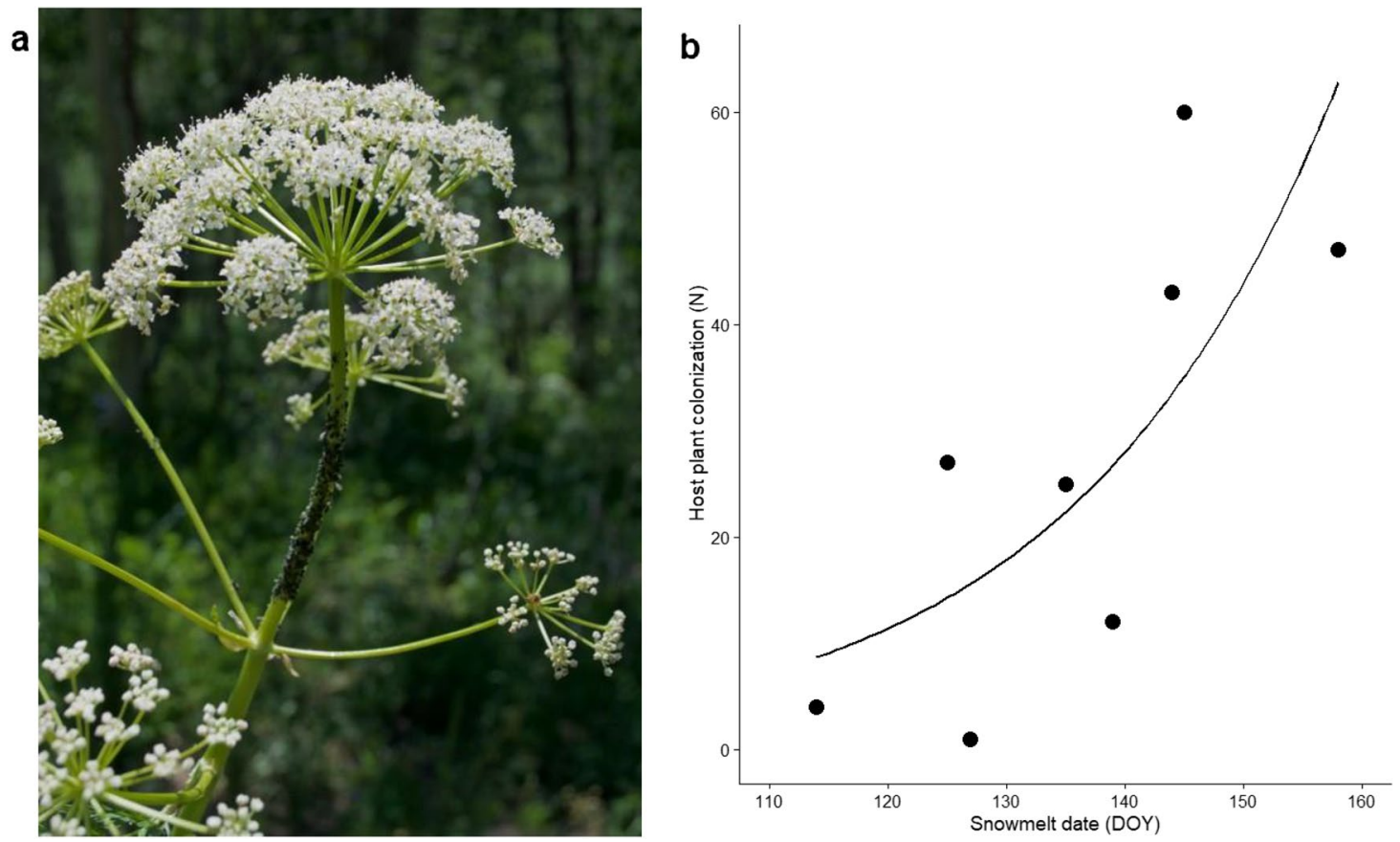

Fig. 1 a Aphid (Aphis asclepiadis) colony on a host plant flowering stalk and b year-to-year variation in colonization of host plant flowering stalks due to snowmelt timing; reproduced from data collected from 2011 to 2019 with methods described in Mooney et al. (2019) 


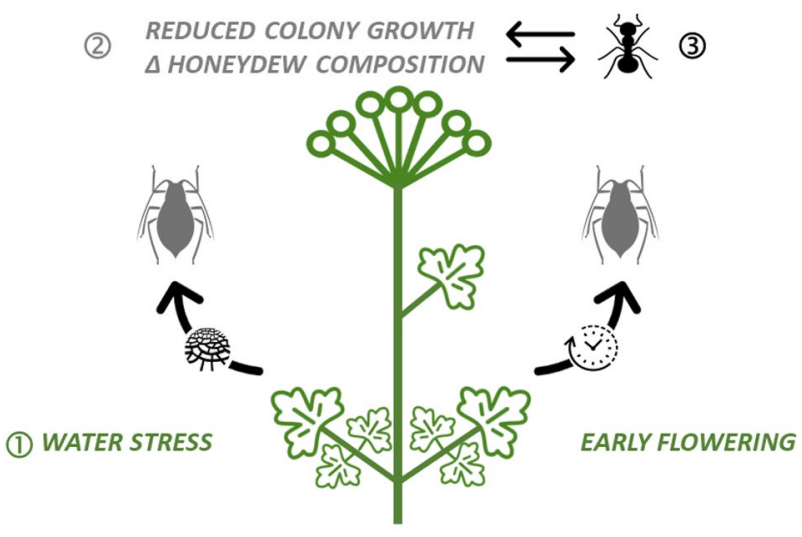

LOW SOIL MOISTURE $\rightarrow$ ADVANCED PHENOLOGY EARLY SNOWMELT

Fig. 2 Hypothesized mechanisms by which early snowmelt could reduce aphid abundance: (1) early loss of snow will reduce soil moisture and advance phenology, leading to drought stressed host plants with earlier flowering, (2) aphid colonies on these plants will have reduced growth and different honeydew compositions, and (3) ants may mediate how aphids respond to host plant quality

et al. 2019). In the Rocky Mountains, early loss of snow cover contributes to drought conditions and early senescence of vegetation (Harpold 2016; Berkelhammer et al. 2017). Host plant water stress can reduce aphid colony growth, and older or senescing tissues present aphids with physical barriers to feeding or phloem sap of lower quality (Pritchard et al. 2007). While some aphids are classified as 'senescence feeders', whereby stressed or senescent host plants support larger colonies (White 2015), A. asclepiadis is instead an example of a 'flush feeder', given its sequential colonization of host plants during their flowering stages (Addicott 1978, 1981).

We also considered how snowmelt timing would affect the ant-aphid mutualism, given its importance in determining the abundance of $A$. asclepiadis on L. porteri (Mooney et al. 2016). We hypothesized that honeydew production and composition by colonies would reflect differences in host plant quality induced by snowmelt timing. Aphids feeding on drought stressed host plants commonly have reduced honeydew production (Hale et al. 2003). Changes in honeydew composition in response to host plant drought stress are less predictable. Aphids polymerize phloem sap sucrose as an osmoregulatory mechanism (Pritchard et al. 2007), so sugar composition in honeydew may differ with host plant water status. For amino acids, the relationship between honeydew and plant phloem sap composition is reciprocal and complex. Aphids excrete a subset of the amino acids present in phloem sap (Douglas 2006), and aphid feeding itself can induce changes in amino acid content of phloem sap (Leroy et al. 2011). Because plant stage affects phloem sap quality, advanced host plant phenology could also play a role in honeydew composition (Douglas 1993). For example, phloem from young bird cherry (Prunus padus) leaves provided aphids with more amino acids than older or senescent leaves (Sandström 2000). Aphids are highly efficient at amino acid uptake, so these phloem sap changes are not always detected in honeydew amino acids (e.g., Quental et al. 2005). Nevertheless, if honeydew changes translate to reduced rates of ant attendance, lack of predator protection could reinforce low aphid abundance in early snowmelt conditions. Lastly, we hypothesized that mutualism with ants would mediate how aphid abundance responded to host plant quality. We predicted lowest aphid abundance on host plants in early snowmelt conditions without ant protection from natural enemies. Top-down and bottom-up effects commonly interact to determine aphid abundance (Mooney et al. 2012). For example, Stadler et al. (2002) found ant presence to effectively erase differences in quality between host plant stages in the obligately myrmecophilous aphid Metopeurum fuscoviride. More broadly, ants frequently mediate how aphid abundances respond to other global change phenomena (Blanchard et al. 2019).

To test these hypotheses, we experimentally added snow and water to replicate plots in 2018 following the designs of similar field manipulations of these factors (Wipf and Rixen 2010; Dorji et al. 2013; Zhu et al. 2014). The snowpack for our study area was less than $60 \%$ of the 30 -year (1981-2010) median snow water equivalents (SWE) in 2018 (Natural Resource Conservation Service 2019). Timing of snow cover loss was correspondingly advanced at our site, with the date of first bare ground occurring 16 days earlier than the long-term (1974-2019) average. By experimentally adding snow, we created host plants with reduced water stress relative to ambient conditions. However, snow addition experiments can also alter flowering phenology (Wipf and Rixen 2010), which could affect quality for our inflorescence-feeding aphid species. To assess role of water stress relative to effects due to phenology, we also added water to replicate plots. If host plant water stress is largely responsible for reduced aphid abundance in early snowmelt years, then adding water would have the same impacts on host plant quality and the anti-aphid mutualism. Alternatively, if host plant phenology also determined aphid abundance, then we would expect unique responses when drought stress is relieved.

\section{Materials and methods}

\section{Study species and site}

We conducted our research near the Rocky Mountain Biological Laboratory (RMBL; 39 $\left.01^{\prime} 38.77^{\prime \prime} \mathrm{N}, 107^{\circ} 03^{\prime} 10.50^{\prime \prime} \mathrm{W}\right)$ in Gunnison County, Colorado. The host plant Ligusticum 
porteri (Apiaceae) is a perennial forb consisting of dissected leaves and flowering stalks that emerge from an underground rhizome (Weber and Wittmann 2001). Flowering stalks have a terminal umbel with one to many subtending axial umbels and large leafy bracts. The aphid Aphis asclepiadis colonizes the flowering stalks beginning in late June (Addicott 1981; Lagos-Kutz et al. 2016). A. asclepiadis aphids form a mutualism with several species of ants, and this mutualism drives aphid abundance by protecting colonies from predation (Mooney et al. 2016). Aphid natural enemies in this system include parasitic chalcid and braconid wasps, adult mirid bugs, syrphid and chamaemyiid flies, lacewings, and coccinellid beetles (Kummel et al. 2013; Mooney et al. 2016; Mound and O’Donnell 2017).

\section{Experimental design}

We experimentally altered snow cover and soil moisture in replicate plots $(N=9)$ of host plants to determine their multitrophic effects on aphid abundance. On April 29, 2018, we experimentally added snow to three replicate plots $(3 \mathrm{~m} \times 3 \mathrm{~m})$ from drifts at least $15 \mathrm{~m}$ away (Supplemental Fig. 1). We measured the volume of water added as snow by coring snow addition and untreated plots with a metal cylin$\operatorname{der}(C=0.5 \mathrm{~m})$, melting the snow sampled, and measuring resulting water. Relative to the untreated plots, we increased the amount of water on snow addition plots by $107 \%$ (Mean untreated $=2587.2 \mathrm{~L} \mathrm{plot}^{-1} \pm 109.8$ S.E., Mean snow addition $=4930.7 \mathrm{~L} \mathrm{plot}^{-1} \pm 250.5$ S.E.). By placing a time-lapse camera in the field, the snow addition plot retained snow cover for two more days than the untreated plot. In June of 2018, we randomly assigned each of the untreated plots to either ambient $(n=3)$ or water addition $(n=3)$ treatment. For plots assigned to water addition, we added $3.5 \mathrm{~L}$ of water every 3 days to water-treated plots (June 9-July 6). After the start of monsoonal rains, $3.5 \mathrm{~L}$ were added once weekly to supplement rainfall (July 9-July 30). This water addition amount has successfully elevated soil moisture around similarly-sized perennial plants in other experimental studies in our study area (Gallagher and Campbell 2017). Host plants in ambient plots received no additional treatment. We measured soil moisture at three locations surrounding each host plant using a $20.3 \mathrm{~cm}$ TDR probe (FieldScout, Spectrum Technologies, Aurora, IL USA) on two dates (June 19 and July 24). These data include all plants $(N=92)$ in all plots.

\section{Responses to snow and water addition}

We measured host plant and insect responses to water and snow addition treatments: emergence of flowering stalks, flowering phenology, photosystem II efficiency (PE), basal leaf senescence, foliar abscisic acid (ABA) content and seed set. We counted the number of flowering stalks per plant in each plot until complete emergence in June. For flowering phenology, we classified the phenological stage of terminal umbels each week from June 11 through July 3 using a 0-6 scale, where 0 represent umbels enclosed by bracts, 4 is flowering and 6 represents all petals are dehisced (Robinson et al. 2017). These data include only plants with flowering stalks $(N=83)$. To determine how host plant treatments could affect aphid abundance, we counted the numbers of apterous aphids and alates on the flowering stalks of each host plant during the weekly censuses of flowering phenology. Spontaneous colonization of host plant flowering stalks by aphids was low: only 18 of 83 host plants with flowering stalks were colonized, and only 7 of these colonies persisted for 1 week.

We used a non-destructive meter (EARS mini Plant Photosynthesis Meter, EARS LTD, Delft NE) to measure photosystem efficiency of upper bracts on flowering stalks. We recorded the mean of three replicate measurements taken from adaxial bract surfaces on June 20 and July 16. We collected one lower bract from each of 48 flowering stalks on June 29, 2018 and kept these leafy bracts on ice in a cooler until frozen at $-20{ }^{\circ} \mathrm{C}$ for storage. We then analyzed molar abscisic acid content per mg of leaf fresh weight ([ABA] M $\mathrm{mg} \mathrm{FW}^{-1}$ ) using the enzyme-linked immunoassay (ELISA) method outlined in Heschel et al. (2014). On July 28, 2018, we assessed basal leaf senescence of plants by counting the proportion of senescent leaves out of the total number of leaves for the subset of plants $(N=77)$ used in the aphid assays described below. On August 1, 2018, we collected the terminal umbels from each of 60 randomly selected plants. These umbels were placed in paper bags, and seed set was quantified as the number of seeds per flower, which were counted under low $(2 \times)$ magnification.

\section{Effects on the ant-aphid mutualism}

Given the low rate of spontaneous colonization, we used experimentally created aphid colonies to determine (1) the effects of host plant treatments on benefits exchanged in the ant-aphid mutualism and (2) how ant presence mediated aphid responses. To establish these colonies, we added five field-collected apterous aphids and one alate to each of 77 host plants with flowering stalks on July 12 . We did not include flowering stalks whose terminal umbels were completely senesced or colonized by aphids at this time. These aphids were introduced to umbels using a fine-haired brush, allowing them to walk off the brush and into the umbel. To exclude flying predators, we enclosed added aphids in an organza bag during colony establishment. To exclude ants, we wrapped stems with tape coated in an insect barrier (Tanglefoot, Scott's Corporation, Marysville, $\mathrm{OH}$ ). One colony failed to establish when an adult lygus was accidently enclosed in the bag, reducing the total sample size $(N=76)$. 
On July 14, we removed organza bags from all colonies. From a randomly selected half of the colonies $(n=38)$, we removed insect barriers, allowing ants to access colonies. This created a factorial combination of ant tending and host plant treatment, which allowed us to determine how ant presence mediated the effects of host plant treatment on aphid colony growth. Ants accessed one colony in the ant exclusion treatment using adjacent flowering stalks, and henceforth we considered this colony as ant tended. We counted the number of apterous aphids, alates, tending ants and other insects every 4 days until July 26.

To test for differences in trophic benefits to ants, we compared deposition and composition of honeydew collected from the experimental aphid colonies. On July 30, we placed aluminum foil squares $\left(100 \mathrm{~cm}^{2}\right)$ below extant colonies $(N=50)$ and left them for $24 \mathrm{~h}$. During this time, we excluded ants from all colonies using the barrier described above. Upon collection, we placed the foils in individual plastic bags and kept them in a cooler until frozen in the laboratory. We measured honeydew deposition by counting the number of droplets under a stereo dissection scope (EZ4 HD with LED, Leica Microsystems) with an image-analysis program (ImageJ, National Institutes of Health, Washington, DC). We divided the foils into fourths, removed the honeydew from one section using ultrapure water, and then analyzed the composition of extracts using high performance liquid chromatography tandem mass spectrometry (LC-MS/ MS). We quantified the concentrations of six sugars (fructose, glucose, sucrose, trehalose, melezitose and raffinose) and five amino acids (glutamic acid, glutamine, aspartic acid, serine and asparagine), which are common components of honeydew (Fischer et al. 2002; Byrne et al. 2003; Pringle et al. 2014). Details of instrumentation and analytical methods are described in Mooney et al. (2019).

\section{Data analysis}

We used a repeated measures approach to test for differences among treatments (ambient, snow addition and water addition) in plant responses measured on more than one date: soil moisture, flowering phenology, and photosystem II efficiency. The mixed effects model included the fixed effects of host plant treatment (ambient, snow addition and water addition) and day of year while accounting for both plant and plot as random effects. We created models and performed significance testing (Type-III ANOVA with Satterthwaite's method) using the lmerTest package (Kuznetsova et al. 2017). For significant $(p<0.05)$ host plant treatmentby-date interactions, we performed post hoc slope contrasts using the 'emtrends()' function from the emmeans package (Lenth 2019).
For host plant responses with a single measurement (basal leaf senescence, foliar ABA concentration, and seed set), we created mixed effects models that included fixed effects of treatment (ambient, snow addition and water addition) and random effects of plot. For the analysis of foliar ABA concentration, an outlier analysis revealed three data points were far outside the range of measurement values; these data points were removed from the data set prior to analysis. We created models and performed significance testing using lmerTest as described above. For significant $(p<0.05)$ host plant treatment effects, we performed post hoc testing with $p$-value adjustment for multiple comparisons using the 'emmeans()' function (Lenth 2019).

We determined how host plant treatment (ambient, snow addition, and water addition) influenced the likelihood of spontaneous aphid colonization $(\mathrm{Y} / \mathrm{N})$ using a general linear mixed effect model (Qian 2017). We created the model using binomially-distributed errors in the 'glmer()' function of the lmerTest package (Kuznetsova et al. 2017). Model terms included the fixed effect of host plant treatment, the random effect of plot and the number of flowering stalks as a covariate, given that plants with more flowering stalks would have a greater likelihood of colonization (Breton and Addicott 1992b). We performed significance testing using the 'Anova()' function from the car package (Fox and Weisberg 2019).

To test for host plant treatment effects on the ant-aphid mutualism, our analysis approach varied among responses. We again used repeated measures analysis to determine how increases in colony size over time varied with host plant treatment (ambient, snow addition and water addition) and ant presence $(\mathrm{Y} / \mathrm{N})$ as explanatory variables. In the subset of colonies with ants, we tested for differences in ant recruitment using analysis of covariance. These models included aphid colony size as a covariate and plot as a random effect. Significant aphid colony size-by-host plant treatment interactions indicate difference in ant recruitment to colonies among treatments (Mooney and Agrawal 2008). For count variables, we used the 'glmer()' function to specify Poisson-distributed errors when testing for differences in aphid colony growth (Qian 2017). We checked for overdispersion of these count data using the 'dispersion_glmer' function from the blmeco package (Korner-Nievergelt et al. 2015). When found ( $>1.4$ ), we added an observation-level random effect (Harrison 2014). Significance testing was performed using the 'Anova()' function from the car package (Fox and Weisberg 2019). We also tested how host plant treatment and ant presence affected the total number of natural enemies observed on the experimental colonies. Most of the experimental colonies had no observed natural enemies $(n=43)$. Therefore, we used a zero-inflated model to determine how total natural enemy abundance varied with host plant treatment and ant presence (Zeileis et al. 2008; Jackman 2017). 
We tested how the total number of honeydew droplets deposited on foils in $24 \mathrm{~h}$ varied with host plant treatment and ant presence. Given the overdispersion of these count data, we created a negative binomial model using the 'neg. bin()' function from the MASS package (Venables and Ripley 2002). The model included aphid colony size as a covariate plus host plant treatment and ant presence as explanatory variables. Multiple analysis of variance (MANOVA) was used to analyze variation among treatments in the sugars and amino acid composition of honeydew extracts. To account for variation in the amount of honeydew on each foil, we divided the concentration of each sugar and amino acid by the number of honeydew droplets extracted. We created the model using the 'manova()' function in R, and then performed univariate tests for individual sugar and amino acid responses using the 'summary.aov()' function. The MANOVA model included host plant treatment and ant presence as explanatory variables. We also included aphid colony size at the time of collection as covariate, given that aphid density itself may induce changes in phloem sap composition (Hodge et al. 2013). Prior to analysis, we checked for multivariate normality of the response variables using the Shapiro-Wilk test, which we performed using the 'mshapiro.test()' function from the mvtnorm package (Genz et al. 2019). When we failed to support multivariate normal distribution $(p<0.05)$, the data were natural log transformed. We performed all of the above analyses in $\mathrm{R}$ ( $\mathrm{R}$ Foundation for Statistical Computing 2020).

\section{Results}

\section{Responses to snow and water addition}

Addition of water or snow significantly increased soil moisture (Fig. 3) but did not affect flowering phenology of host plants. Soil moisture declined over the measurement period, but this was largely consistent among treatments, as indicated by non-significant host plant treatment-by-date interaction (Table 1a). Overall, water addition increased mean soil moisture by $44 \%$ relative to ambient conditions $(t$-value $=2.851, p=0.005)$. Snow addition increased mean soil moisture by $19 \%$ relative to ambient conditions, although this contrast was not significant when June and July values were considered together $(t$-value $=0.576, p=0.566)$. Our index tracked flowering phenology from June through July (Fig. 4), with most flowering stalks reaching full flowering by July 3 (DOY: 184) regardless of treatment. However, neither the main effect of host plant treatment on flowering phenology or the treatment-by-date interaction were significant (Table 1b). As with flowering phenology, we detected changes over time in photosystem II efficiency $\left(F_{\mathrm{v}} / F_{\mathrm{m}}\right)$, but no effects of host plant treatment were apparent (Table 1c).

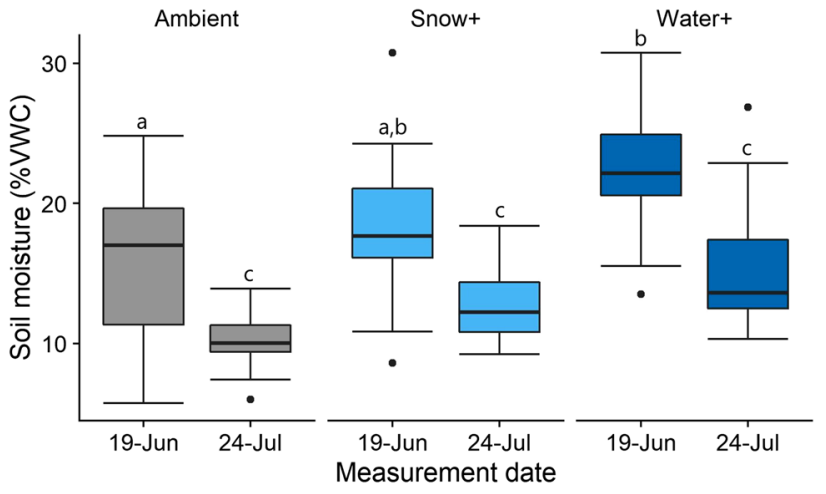

Fig. 3 Volumetric water content (\%) of soil around host plants as measured by a TDR probe on two measurement dates during the field experiment; boxplots depict medians, interquartile ranges, and outliers. Letters indicate results of post hoc contrasts of means; different letters above boxplots indicate significance differences $(p<0.05)$ after Tukey correction for multiple comparisons

Similarly, the likelihood of spontaneous aphid colonization did not vary with host plant treatment (Table 2a).

Basal leaf senescence, foliar abscisic acid concentration and seed set all indicated effects of host plant treatment (Fig. 5). Under ambient conditions, host plants showed greater senescence of basal leaves in July than when snow or water were added $\left(F_{3,74}=18.567, p<0.001\right)$. Post hoc contrasts revealed that, host plants with water addition had a 79\% lower proportion of senesced basal leaves $(t$-value $=-3.786, p=0.020)$ and host plants with snow addition had a $66 \%$ lower proportion of senesced basal leaves $(t$-value $=-3.259, p=0.041)$ relative to ambient conditions. Water and snow addition treatments resulted in similar levels of basal leaf senescence $(p>0.05)$. We observed a trend $(p<0.10)$ for foliar abscisic acid (ABA) concentration to vary among host plant treatments $\left(F_{2,6}=4.565, p=0.062\right)$. ABA was higher in the bracts of ambient host plants relative to those with water $(t$-value $=-2.656, p=0.039)$ or snow addition $(t$-value $=-2.574, p=0.041)$. However, foliar ABA was similarly low between host plants that received either water or snow addition $(p>0.05)$. Seed set significantly differed among host plant treatments $\left(F_{2,56}=3.993, p=0.024\right)$. Relative to ambient conditions, snow addition increased seed set of host plants by $171 \%$ and water addition increased seed set by $150 \%$.

\section{Effects on the ant-aphid mutualism}

Ant presence modified how aphid colony growth responded to host plant treatment, i.e., we observed a significant ant presence-by-host plant treatment-by-date interaction (Table 2b). When ants were present, differences in growth of colonies over time appeared. Post hoc contrasts of slopes showed that colonies on ambient host plants grew less over 
Table 1 Statistical results from general linear mixed effects models for changes in soil moisture, flowering phenology, and photosystem II efficiency in response to host plant treatments

\begin{tabular}{llll}
\hline Model term & a. Soil moisture $($ VWC $\%)$ & b. Flowering phenology & c. Photosystem II efficiency \\
\hline Treatment & $F_{2,81}=4.482, p=0.014$ & $F_{2,247}=0.368, p=0.692$ & $F_{2,69}=1.177, p=0.314$ \\
Date & $F_{1,77}=164.294, p<0.001$ & $F_{1,249}=2112.719, p<0.001$ & $F_{1,66}=47.087, p<0.001$ \\
Treatment $\times$ date & $F_{2,77}=2.270, p=0.110$ & $F_{2,249}=0.391, p=0.677$ & $F_{2,66}=1.013, p=0.369$ \\
\hline
\end{tabular}

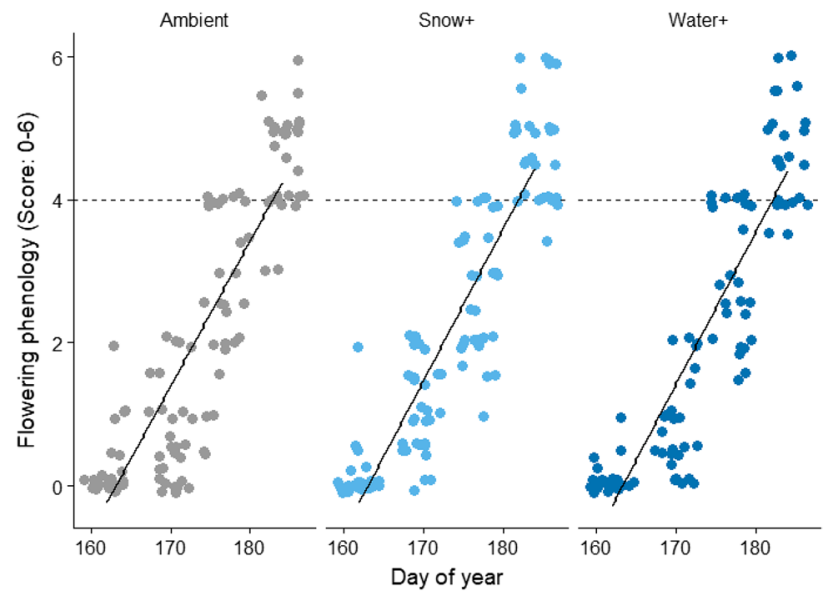

Fig. 4 Flowering phenology scores for host plant flowering stalks observed from June through July; horizontal dashed line shows flowering stage 4 , which corresponds to full anthesis. Points are jittered to make individual observations visible

time than colonies on snow (slope difference: -0.0745 ; $z$-ratio $=-2.448, p=0.038$ ) or water addition (slope difference $=-0.1492 ; z$-ratio $=-4.911, p<0.001$ ) host plants. Colony growth over time was also lower on host plants with water addition than those with snow addition (slope difference: $-0.0746 ; z$-ratio $=-2.465, p=0.037$ ). When ants were absent, no post hoc contrasts of slopes were statistically significant $(p<0.05)$. However, there was a trend for growth to be lower on host plants in ambient conditions relative those with water addition (slope difference: -0.0654 ; $z$-ratio $=-2.197, p=0.072$ ). Colonies on ambient host plants and those with snow addition had statistically similar growth (slope difference: $-0.0250 ; z$-ratio $=-0.848$, $p=0.673$ ). Likewise, growth of colonies on snow and water addition host plants did not differ (slope difference: 0.040; $z$-ratio $=0.029, p=0.345$ ) (Fig. 6).

Overall, we counted 320 ants tending experimental aphid colonies, with the majority (69.6\%) of individuals being Tapinoma sessile and the remainder being equally comprised of Formica fusca and Formica podzolica. As expected, the number of ants tending experimental colonies increased with aphid colony size (Table 2c). However, we found a trend $(p<0.10)$ for host plant treatment to affect the total number of ants tending colonies. Colonies on ambient host plants tended to recruit more ants than colonies on host plants with either water or snow addition (Fig. 7). Host plant treatment also affected the numbers of natural enemies counted during colony growth (Fig. 8). We counted 49 aphid natural enemies in total, and nearly half of these $(n=24)$ were adult mirid bugs. The remainder of natural enemies observed consisted of coccinellid beetle larvae and adults $(n=14)$, braconid wasps $(n=8)$, chamaemyiid flies $(n=2)$ and one lacewing. Relative to ambient host plants, colonies on host plants with snow addition tended to have more instances where we observed zero natural enemies $(z$-value $=-1.687, p=0.092)$. When natural enemies did occur, colonies on snow addition host plants had $40 \%$ fewer than on ambient host plants $(z$-value $=1.980, p=0.048)$. No other terms from the either the zero-hurdle model or the count model indicate significant effects of either host plant treatment or ants on natural enemy abundance.

The overall amount of honeydew droplets produced by colonies was not affected by host plant treatment or ant presence. Deposition of honeydew droplets on collection foils tended to increase with aphid colony size (Table 2d), but neither host plant treatment nor ant presence influenced this $(p>0.05)$. We observed changes in the sugar and amino acid composition of honeydew droplets due to both host plant treatment and ant presence (Supplemental Table 1). Concentrations of the sugars in honeydew droplets generally increased with aphid colony size. However, for the trisaccharide sugars melezitose and raffinose, this increase in concentration with colony size only occurred with ant tending. The disaccharide sugar trehalose also tended to increase with ant tending, but this increase only occurred on host plants with snow addition (Fig. 9). A significant three-way interaction (Aphids $\times$ host plant treatment $\times$ ant presence) suggests changes in overall amino acid composition. However, a lack of statistically significant effects for any individual amino acid concentration makes this result difficult to parse.

\section{Discussion}

Early loss of snow cover is altering ecological communities, and in our study system, aphid colony abundance is reduced by half when snowmelt occurs just 10 days earlier in spring (Robinson et al. 2017; Mooney et al. 2019). This experiment tested the hypothesis that early loss of snow cover reduces 
Table 2 Statistical results for models related to aphid colonization and experimental aphid colonies: likelihood ratio $\chi^{2}$ test statistics and $p$-values obtained from type-III Wald tests

\begin{tabular}{|c|c|c|c|c|c|c|c|}
\hline \multicolumn{2}{|c|}{$\begin{array}{l}\text { a. Spontaneous aphid coloniza- } \\
\text { tion }\end{array}$} & \multicolumn{2}{|c|}{ b. Experimental aphid colony growth } & \multicolumn{2}{|c|}{ c. Ant recruitment } & \multicolumn{2}{|l|}{ d. Honeydew deposition } \\
\hline Model term & $\begin{array}{l}\text { ANOVA } \\
\text { results }\end{array}$ & Model term & $\begin{array}{l}\text { ANOVA } \\
\text { results }\end{array}$ & Model term & $\begin{array}{l}\text { ANOVA } \\
\text { results }\end{array}$ & Model term & $\begin{array}{l}\text { ANOVA } \\
\text { results }\end{array}$ \\
\hline Treatment & $\begin{array}{c}\chi^{2}=2.157, \\
d f=2, \\
p=0.340\end{array}$ & Treatment & $\begin{array}{c}\chi^{2}=1.393, \\
d f=2, \\
p=0.498\end{array}$ & Treatment & $\begin{array}{c}\chi^{2}=4.630, \\
d f=2, \\
p=0.099\end{array}$ & Treatment & $\begin{array}{c}\chi^{2}=1.218, \\
d f=2, \\
p=0.544\end{array}$ \\
\hline Flowering stalks & $\begin{array}{c}\chi^{2}=0.578 \\
d f=1 \\
p=0.447\end{array}$ & Ants & $\begin{array}{c}\chi^{2}=0.222 \\
d f=1 \\
p=0.637\end{array}$ & $\begin{array}{l}\text { Aphid colony } \\
\text { size }\end{array}$ & $\begin{array}{c}\chi^{2}=11.483, \\
d f=1 \\
p<0.001\end{array}$ & Aphid colony size & $\begin{array}{c}\chi^{2}=17.846 \\
d f=1, \\
p<0.001\end{array}$ \\
\hline \multirow[t]{5}{*}{$\begin{array}{l}\text { Flowerings } \\
\text { stalks } \times \text { treat- } \\
\text { ment }\end{array}$} & $\begin{array}{c}\chi^{2}=1.703, \\
d f=2, \\
p=0.427\end{array}$ & Date & $\begin{array}{c}\chi^{2}=1157.357 \\
d f=1 \\
p<0.001\end{array}$ & $\begin{array}{l}\text { Treat- } \\
\text { ment } \times \text { col- } \\
\text { ony size }\end{array}$ & $\begin{array}{c}\chi^{2}=2.962, \\
d f=2 \\
p=0.227\end{array}$ & Ants & $\begin{array}{c}\chi^{2}=0.581, \\
d f=1, \\
p=0.446\end{array}$ \\
\hline & & Treatment $\times$ ants & $\begin{array}{c}\chi^{2}=2.051 \\
d f=1 \\
p=0.359\end{array}$ & & & Treatment $\times$ aphids & $\begin{array}{c}\chi^{2}=1.930, \\
d f=2, \\
p=0.381\end{array}$ \\
\hline & & Treatment $\times$ date & $\begin{array}{c}\chi^{2}=24.122, \\
d f=2, \\
p<0.001\end{array}$ & & & Treatment $\times$ ants & $\begin{array}{r}\chi^{2}=3.868, \\
d f=1,42, \\
p=0.145\end{array}$ \\
\hline & & Ants $\times$ date & $\begin{array}{c}\chi^{2}=14.685, \\
d f=1, \\
p<0.001\end{array}$ & & & Aphids $\times$ ants & $\begin{array}{c}\chi^{2}=0.257, \\
d f=2,40, \\
p=0.223\end{array}$ \\
\hline & & $\begin{array}{l}\text { Treat- } \\
\text { ment } \times \text { date } \times \text { ants }\end{array}$ & $\begin{array}{c}\chi^{2}=10.867, \\
d f=2, \\
p=0.004\end{array}$ & & & $\begin{array}{l}\text { Treat- } \\
\text { ment } \times \text { aphids } \times \text { ants }\end{array}$ & $\begin{array}{c}\chi^{2}=1.244, \\
d f=2,38, \\
p=0.537\end{array}$ \\
\hline
\end{tabular}

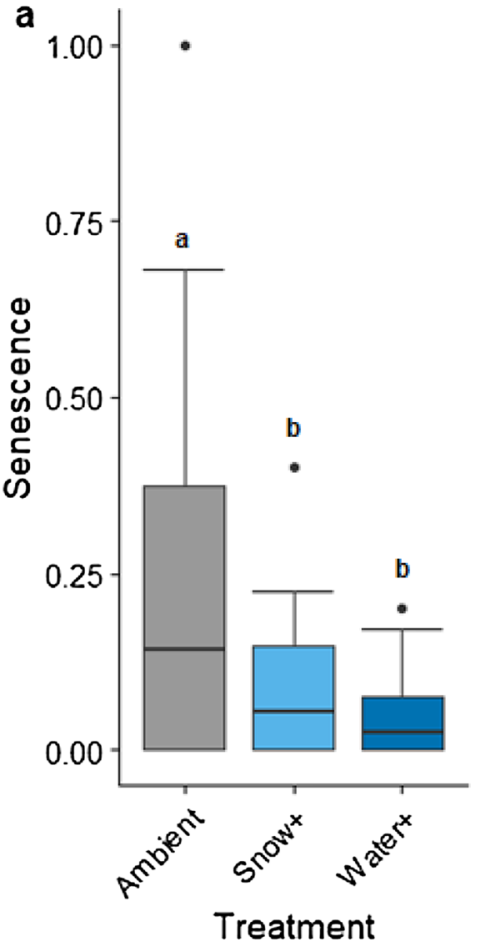

Fig. 5 Responses of host plants to experimental treatments: a proportion of senescent basal leaves in July, b foliar abscisic acid content, and $\mathbf{c}$ seeds produced per flower; boxplots depict median, interquar-

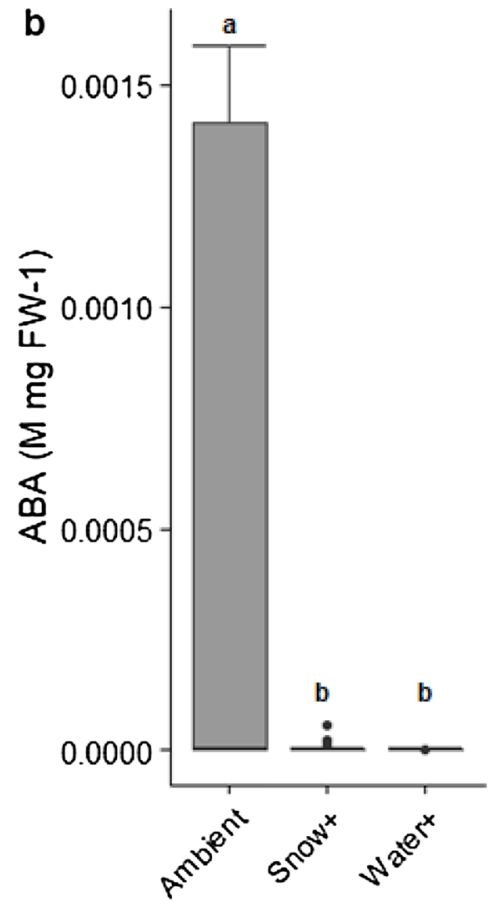

Treatment

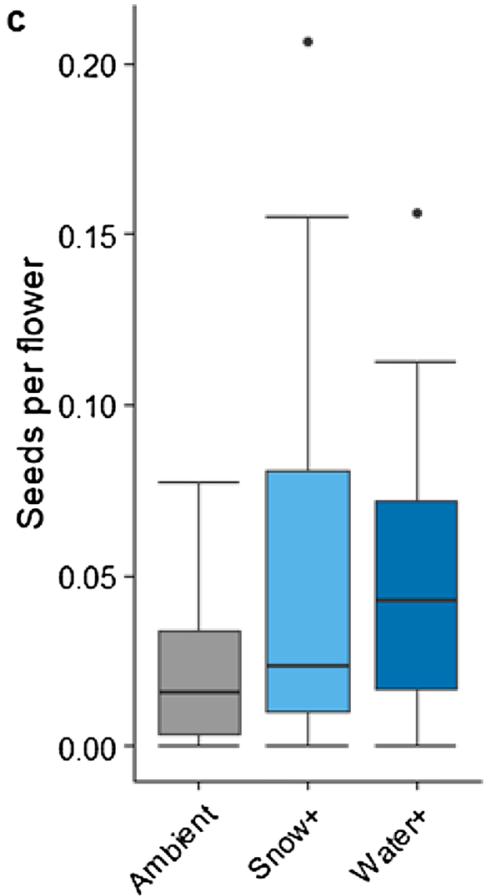

Treatment

tile range and outliers. Letters indicate results of post hoc contrasts of means; different letters above boxplots indicate significance differences $(p<0.05)$ after Tukey correction for multiple comparisons 
Fig. 6 Growth of aphid colonies with and without ant tending on host plants in each treatment (ambient, water addition and snow addition); points are jittered to make individual observations visible. Curves depict general linear models with Poisson-distributed errors

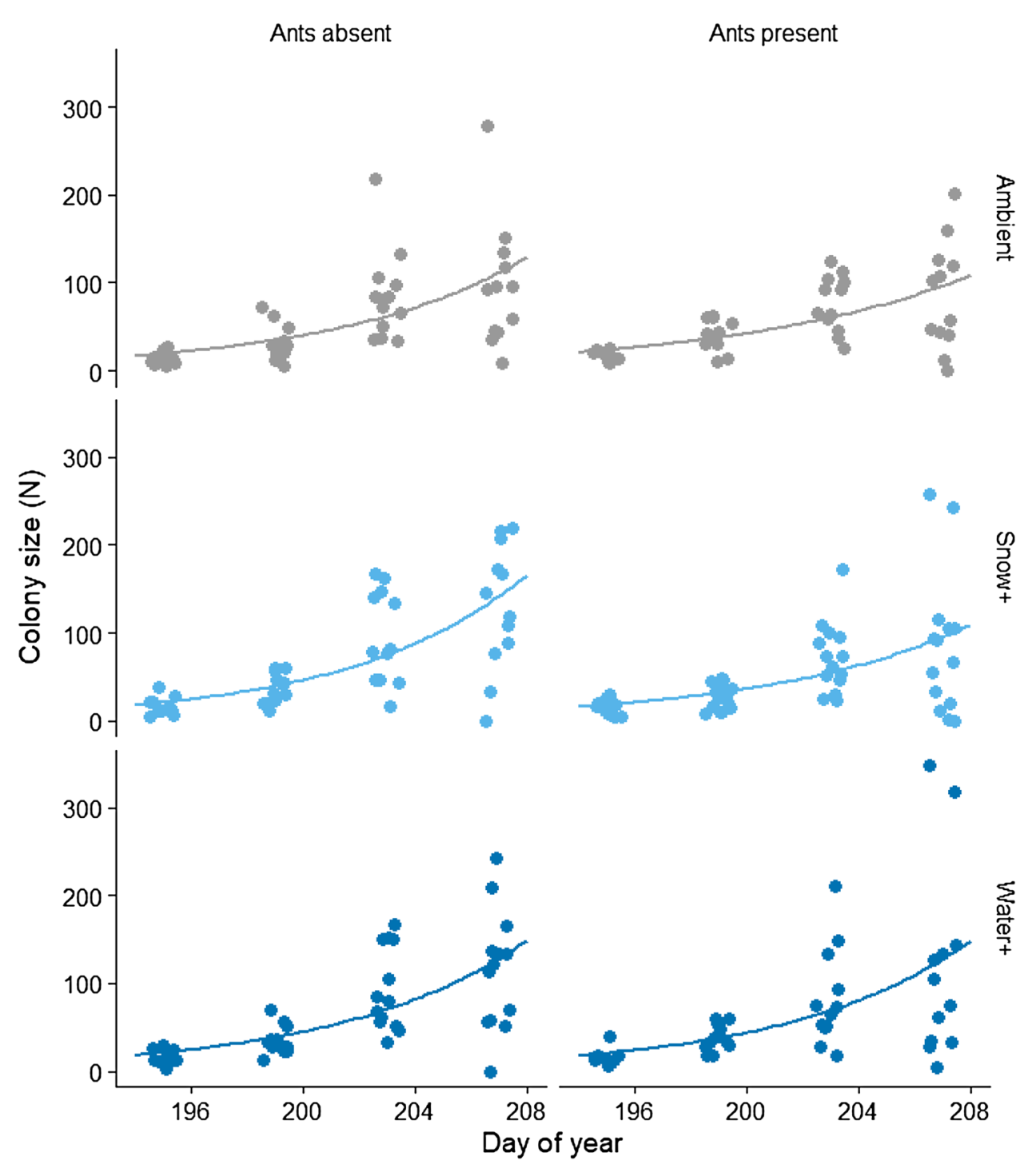

host plant quality by accelerating phenology and inducing water stress. In addition, we predicted that the ant-aphid mutualism would mediate responses of aphids to host plant quality. Our experimental design allowed us to assess the relative impacts of these mechanisms. Adding snow or water similarly reduced water stress in host plants. However, ant presence mediated how aphid colony growth responded to host plant water stress. When tended by ants, experimental aphid colonies grew significantly less on water-stressed host plants. Without ant tending, these colonies grew at similar rates regardless of host plant treatment. Overall, we detected very few plant or insect responses to snow addition that were unique from water addition, suggesting water stress plays a large role in reducing host plant quality.

Host plant drought stress responses reinforce the critical role of snow in providing soil moisture in our subalpine system. In 2017-2018, El Niño-Southern Oscillation (ENSO) conditions brought low snowpack to Colorado (Thakur et al.
2020), and weaker-than-average monsoonal precipitation then reinforced dry conditions (CSU: Colorado Climate Center 2019). Plants in these ambient conditions showed accelerated basal leaf senescence and elevated ABA concentrations, both of which indicate water stress (Heschel et al. 2014). These responses are also related: ABA is an enhancer of leaf senescence, and senescing leaves have increased levels of ABA (Zhang and Zhou 2013). Adding snow in April effectively reduced these key signals of water stress. Later season water addition had identical effects on these host plant responses. However, snow addition did not impact flowering phenology of host plants. While other snow addition experiments have achieved delayed flowering phenology (Wipf and Rixen 2010), an unusually warm spring likely accelerated snow loss and eroded any difference between treatments. Mean maximum temperature in Crested Butte was $4{ }^{\circ} \mathrm{C}$ above the long-term mean maximum temperatures for this area in June (CSU: Colorado Climate Center 


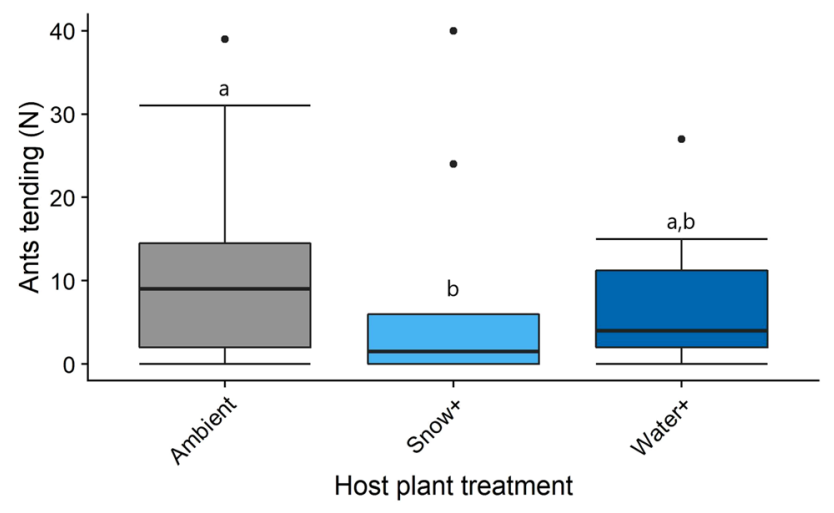

Fig. 7 Effects of host plant treatment on the total number of ants observed tending experimental aphid colonies. Letters indicate results of post hoc contrasts of means; different letters above boxplots indicate a trend $(p<0.10)$ for differences after Tukey correction for multiple comparisons

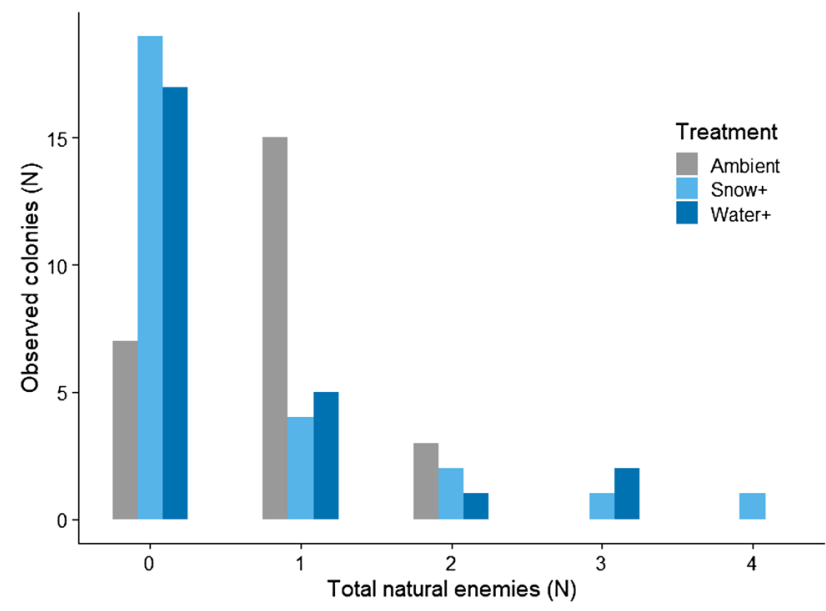

Fig. 8 Histogram of the numbers of experimental aphid colonies with zero through four natural enemies counted during the 12-day growth period

2019). The lack of an impact of our snow addition treatment on flowering phenology is one important limitation of our results. The timing of snowmelt drives $L$. porteri flowering phenology (Iler et al. 2013), and the phenology of flowering stalks could have a much larger impact on aphids or their interactions with other insects than our current study can address. Snow and water addition did impact phenology in a broader sense, given that senescence and seed set are also partly phenological responses. Our results suggest drought stress advances senescence and reduces seed set for $L$. porteri. In other species, these end-of-season processes are similarly mediated by snow cover (Wipf and Rixen 2010). For example, Dorji et al. (2020) found low snow years to limit soil moisture and shorten the length of flowering in alpine

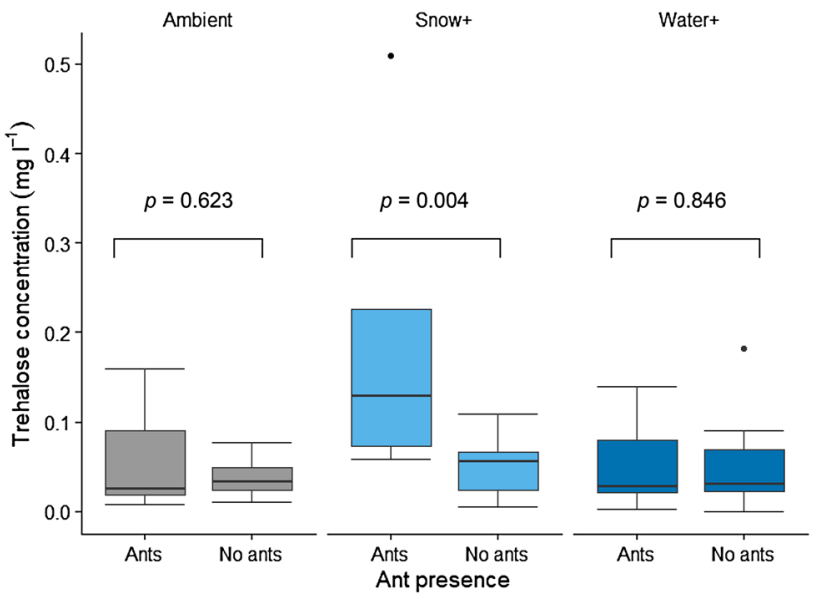

Fig. 9 Concentrations of trehalose in aphid honeydew droplets as determined by HILIC LC MS/MS. $p$-values indicate results of post hoc contrasts of means after Tukey correction for multiple comparisons

Potentilla species. A similar response occurs in Arctic species as well: earlier snow cover loss leads to an earlier peak rather than extending periods of flowering or growth (Rumpf et al. 2014). Such effects have implications for plant fitness and consumers who rely on seasonal availability of seeds.

Growth of experimental aphid colonies demonstrated differences in host plant quality. Host plants under ambient conditions supported colonies that grew more slowly over time than those on snow or water addition host plants. Water stress has several effects on host plants that limit their ability to support aphid colonies (Pritchard et al. 2007). While "senescence feeders" can take advantage of seasonal nutrient redistribution (White 2015), studies have long demonstrated that plants senescing under dry conditions are low-quality hosts for aphids (Kennedy 1958). More recent studies have highlighted phytohormonal mechanisms for this pattern, specifically how abscisic acid induced by water stress regulates responses to aphid attack (Goggin 2007). How ABA interacts with induced defense is species specific, but "crosstalk" can occur whereby ABA upregulates defense pathway components (Morkunas et al. 2011). At a more immediate level, drought may impair the movement of phloem sap, although empirical studies of this effect remain surprisingly rare (Sevanto 2014). Any loss of pressure in the sieve tube elements would impede the ability of aphids to uptake phloem sap (Pritchard et al. 2007). Changes in phloem sap composition may have occurred as well. Senescing basal leaves indicate less photosynthate available for flowering stalks, where the experimental A. asclepiadis colonies exclusively occurred. Overall decreases in the photosystem II efficiency of bracts show seasonal changes in flowering stalks as well. We detected lower seed set for host plants in ambient conditions. Plants increase transport of sugar 
and amino acids during seed filling (Lohaus and Moellers 2000; Corbesier et al. 2001). Colonies on flowering stalks setting seed-i.e., those of host plants with added snow or water-would likely benefit from higher quality phloem sap. We lack data to differentiate among these mechanisms for lowered host plant quality. Future experiments should assay changes in both defensive chemistry and phloem sap composition of $L$. porteri with host plant drought stress.

The ant-aphid mutualism interacted with differences among host plants in complex ways. Ant presence modified how aphids responded to host plant treatment, and host plant treatment altered the benefits exchanged in this mutualism. When tending ants were present, aphid colony growth reflected differences in host plant quality: greater growth occurred on snow addition host plants relative to those with water addition or in ambient conditions. In the absence of ants, colonies grew at largely similar rates regardless of host plant treatment. Surprisingly, experimental aphid colonies also grew at overall higher rates when not tended by ants. In previous field experiments in this system, we have not observed negative effects of ant attendance on aphid colony growth (Mooney et al. 2016, 2019; Robinson et al. 2017). However, in an experimental study near our study site, Petry et al. (2012) also found negative effects of ant attendance on colony growth of Aphis valerianae, which the authors attributed to the costs of ant attendance. Examples of such costs include decreases in per capita fecundity, increases in honeydew excretion and changes in honeydew composition induced by ant attendance (Stadler and Dixon 1998; Yao 2014). Although our data cannot address changes in fecundity, we have evidence that ant attendance changed honeydew composition without changing overall deposition amounts. Specifically, ant-tended aphid colonies produced honeydew enriched in the trisaccharides melezitose and raffinose, both key stimulants to ant feeding that are synthesized in the aphid gut from phloem sap (Völkl et al. 1999; Detrain et al. 2010). Melezitose production comes at a cost to aphid fitness, as demonstrated by differences in colony growth rates and alate production between Aphis fabae clones that vary in melezitose production (Vantaux et al. 2015). Costs of ant attendance are likely to vary over time (Yao 2014), so we might expect results from this study year to vary from previous field experiments in our system. This experiment should be repeated across many years to determine the consistency of ant effects. However, one key caveat is the difficulty of meaningfully replicating snow manipulation across years, which tend to vary dramatically in snow cover. Besides these ant-induced costs, an alternative explanation is that barriers to ants also excluded stemforaging predators. We have no evidence that natural enemy abundance varied with ant exclusion treatment. However, counts of natural enemies were made during the day, which would miss night-foraging predators such as carabid beetles
(Losey and Denno 1998). Future studies should include observations of colonies at night to determine the influence of these predators in our system.

Host plant responses were largely identical between the snow and water addition treatments, but we did see unique insect responses to snow addition. Relative to colonies on other host plants, aphid colonies on host plants with snow addition showed greater growth and elevated levels of trehalose in honeydew when tended by ants. These responses may be related. Trehalose is a common constituent of ant-tended aphid honeydew (Yao and Akimoto 2001; Fischer and Shingleton 2001), and high-density aphid colonies induce production of this disaccharide in Arabidopsis leaves (Hodge et al. 2013). However, ant foragers are largely unresponsive to trehalose (Völkl et al. 1999; Boevé and Wäckers 2003; Detrain et al. 2010), as ants do not recognize trehalose as a sugar source (Fischer and Shingleton 2001). Given that ants reduced colony growth overall, producing a sugar that was not stimulating to ants could benefit colony growth. In this way, a 'feedback loop' may be initiated whereby large colonies on snow addition host plants induced changes in trehalose concentration, which then further enhances colony growth by keeping ant abundance low. What underlying mechanism that would allow this process to occur for colonies on snow addition host plants - but not on host plants in ambient conditions or with water addition-is beyond what can be addressed with our results. Follow up studies should both assess sugar levels within host plants and test for effects of specific sugars on ant behavior.

\section{Conclusions}

Our experimental results provide insights for larger pattern seen in our long-term monitoring, i.e., very few $L$. porteri flowering stalks host aphid colonies in early snowmelt years. In such years, A. asclepiadis would encounter low-quality host plants that senesce early and fail to set seed. Colony growth would be slowed further with the costs associated with mutualism with ants or increased abundance of natural enemies. Colonies could rapidly decline to extinction under these conditions, reducing migrants that might otherwise establish new colonies. At a larger scale than our system, Rocky Mountain plant communities show this same pattern of accelerated senescence when winter precipitation is reduced (Berkelhammer et al. 2017). Given our results, we would expect similar declines for other 'flush feeder' aphid species on different host plants. Reduced aphid abundance has community-wide implications given their roles as competitors, prey, and herbivores (Kearns 1992; Eubanks and Styrsky 2006; Ando et al. 2017). Early predictions forecasted outbreaks in a broad range of herbivorous insects as the climate changes (e.g., Bale et al. 2002). Our results add 
to an increasing collection of studies showing a much more complex response, including declines in a variety of insects driven by changes in multitrophic interactions (Boggs 2016; Leather 2018).

Acknowledgements This research was supported by a grant from the National Science Foundation Division of Environmental Biology to E. Mooney (NSF DEB: 1655914). The National Science Foundation (NSF CHE: 1429567) and Shimadzu Corporation are acknowledged for funds to purchase the LC/MS/MS instrumentation. Additional funding for E. Godtfredsen came from the Colorado College Hevey Fund. We also thank B. Davidson, M. Torabi and S. Donato for help with data collection. We are also grateful to the Research Committee and Science Director Jennie Reithel at the Rocky Mountain Biological Laboratory for permitting this research.

Author contributions All authors contributed to the overall conception of the study. Experimental design and sampling protocols were formulated by SH and EM. Field data collection was performed by SH, EM, JDU, MM, ST, and EG. Data analysis was performed by EM and SH. Laboratory analysis of honeydew was performed by JO and PN. The first draft of the manuscript was written by EM and all authors commented on previous versions of the manuscript. All authors read and approved the final manuscript.

Funding This study was funded by a grant from the National Science Foundation Division of Environmental Biology to E. Mooney (NSF DEB: 1655914), a grant from The National Science Foundation (NSF CHE: 1429567) to J. Owens, and Shimadzu Corporation are acknowledged for funds to purchase the LC/MS/MS instrumentation. Additional funding for E. Godtfredsen came from the Colorado College Hevey Fund.

Data availability To be hosted by the Rocky Mountain Biological Laboratory online databases; predicted availability of this data repository is May 2020.

\section{Compliance with ethical standards}

Conflict of interest The authors declare that they have no conflict of interest.

Open Access This article is licensed under a Creative Commons Attribution 4.0 International License, which permits use, sharing, adaptation, distribution and reproduction in any medium or format, as long as you give appropriate credit to the original author(s) and the source, provide a link to the Creative Commons licence, and indicate if changes were made. The images or other third party material in this article are included in the article's Creative Commons licence, unless indicated otherwise in a credit line to the material. If material is not included in the article's Creative Commons licence and your intended use is not permitted by statutory regulation or exceeds the permitted use, you will need to obtain permission directly from the copyright holder. To view a copy of this licence, visit http://creativecommons.org/licenses/by/4.0/.

\section{References}

Addicott JF (1978) The population dynamics of aphids on fire weed: a comparison of local populations and metapopulations. Can J Zool 56:2554-2564. https://doi.org/10.1139/z78-343
Addicott J (1981) Synonymy of Aphis heraclella Davis 1919 with Aphis helianthi Monell 1879 (Homoptera: Aphididae). Can Entomol 113:167-169

Ando Y, Utsumi S, Ohgushi T (2017) Aphid as a network creator for the plant-associated arthropod community and its consequence for plant reproductive success. Funct Ecol 31:632-641. https:// doi.org/10.1111/1365-2435.12780

Bale JS, Masters GJ, Hodkinson ID et al (2002) Herbivory in global climate change research: direct effects of rising temperature on insect herbivores. Glob Change Biol 8:1-16. https://doi.org/10 .1046/j.1365-2486.2002.00451.x

Banfield-Zanin JA, Leather SR (2015) Reproduction of an arboreal aphid pest, Elatobium abietinum, is altered under drought stress. J Appl Entomol 139:302-313. https://doi.org/10.1111/jen.12159

Berkelhammer M, Stefanescu IC, Joiner J, Anderson L (2017) High sensitivity of gross primary production in the Rocky Mountains to summer rain. Geophys Res Lett 44:3643-3652. https://doi. org/10.1002/2016GL072495

Blanchard S, Lognay G, Verheggen F, Detrain C (2019) Today and tomorrow: impact of climate change on aphid biology and potential consequences on their mutualism with ants. Physiol Entomol 44:77-86. https://doi.org/10.1111/phen.12275

Boevé JL, Wäckers FL (2003) Gustatory perception and metabolic utilization of sugars by Myrmica rubra ant workers. Oecologia 136:508-514. https://doi.org/10.1007/s00442-003-1249-9

Boggs CL (2016) The fingerprints of global climate change on insect populations. Curr Opin Insect Sci 17:69-73. https://doi. org/10.1016/j.cois.2016.07.004

Breton LM, Addicott JF (1992a) Density-dependent mutualism in an aphid-ant interaction. Ecology 73:2175-2180. https://doi. org/10.2307/1941465

Breton LM, Addicott JF (1992b) Does host-plant quality mediate aphid-ant mutualism? Oikos 63:253. https://doi. org/10.2307/3545385

Byrne DN, Hendrix DL, Williams LH (2003) Presence of trehalulose and other oligosaccharides in hemipteran honeydew, particularly Aleyrodidae. Physiol Entomol 28:144-149. https://doi.org /10.1046/j.1365-3032.2003.00310.x

Corbesier L, Havelange A, Lejeune P et al (2001) N content of phloem and xylem exudates during the transition to flowering in Sinapis alba and Arabidopsis thaliana. Plant Cell Environ 24:367-375

CSU: Colorado Climate Center (2019) Colorado Climate Center. In: Clim. Norm. Maps Graphs. https://climate.colostate.edu/norma ls.html. Accessed 6 Apr 2019

Detrain C, Verheggen FJ, Diez L et al (2010) Aphid-ant mutualism: how honeydew sugars influence the behaviour of ant scouts. Physiol Entomol 35:168-174. https://doi.org/10.111 $1 /$ j.1365-3032.2010.00730.x

Dorji T, Totland $\varnothing$, Moe SR et al (2013) Plant functional traits mediate reproductive phenology and success in response to experimental warming and snow addition in Tibet. Glob Change Biol 19:459-472. https://doi.org/10.1111/gcb.12059

Dorji T, Hopping KA, Meng F et al (2020) Impacts of climate change on flowering phenology and production in alpine plants: the importance of end of flowering. Agric Ecosyst Environ 291:106795. https://doi.org/10.1016/j.agee.2019.106795

Douglas AE (1993) The nutritional quality of phloem sap utilized by natural aphid populations. Ecol Entomol 18:31-38. https:// doi.org/10.1111/j.1365-2311.1993.tb01076.x

Douglas A (2006) Phloem-sap feeding by animals: problems and solutions. J Exp Bot 57:747-754. https://doi.org/10.1093/jxb/ erj067

Eubanks MD, Styrsky JD (2006) Ant-hemipteran mutualisms: keystone interactions that alter food web dynamics and influence plant fitness. In: Brodeur J, Boivin G (eds) Trophic and guild in biological interactions control. Progress in biological 
control, vol 3. Springer, Dordrecht, pp 171-189. https://doi. org/10.1007/1-4020-4767-3_8

Fischer MK, Shingleton AWA (2001) Host plant and ants influence the honeydew sugar composition of aphids. Funct Ecol 15:544-550. https://doi.org/10.1046/j.0269-8463.2001.00550.x

Fischer MK, Völkl W, Schopf R, Hoffmann KH (2002) Age-specific patterns in honeydew production and honeydew composition in the aphid Metopeurum fuscoviride: implications for ant-attendance. J Insect Physiol 48:319-326. https://doi.org/10.1016/S0022 $-1910(01) 00179-2$

Fox J, Weisberg S (2019) An R companion to applied regression, 3rd edn. Sage Publications

Fuchs B, Breuer T, Findling S et al (2017) Enhanced aphid abundance in spring desynchronizes predator-prey and plant-microorganism interactions. Oecologia 183:469-478. https://doi. org/10.1007/s00442-016-3768-1

Gallagher MK, Campbell DR (2017) Shifts in water availability mediate plant-pollinator interactions. New Phytol 215:792-802. https://doi.org/10.1111/nph.14602

Genz A, Bretz F, Miwa T et al (2019) mvtnorm: multivariate normal and $t$ distributions. $R$ package version $1.0-10$

Goggin FL (2007) Plant-aphid interactions: molecular and ecological perspectives. Curr Opin Plant Biol 10:399-408. https://doi. org/10.1016/j.pbi.2007.06.004

Guo H, Sun Y, Peng X et al (2016) Up-regulation of abscisic acid signaling pathway facilitates aphid xylem absorption and osmoregulation under drought stress. J Exp Bot 67:681-693. https://doi.org/10.1093/jxb/erv481

Hale BK, Bale JS, Pritchard J et al (2003) Effects of host plant drought stress on the performance of the bird cherry-oat aphid, Rhopalosiphum padi (L.): a mechanistic analysis. Ecol Entomol 28:666-677. https://doi.org/10.1111/j.1365-2311.2003.00563.x

Harpold AA (2016) Diverging sensitivity of soil water stress to changing snowmelt timing in the Western U.S. Adv Water Resour 92:116-129. https://doi.org/10.1016/j.advwa tres.2016.03.017

Harrison XA (2014) Using observation-level random effects to model overdispersion in count data in ecology and evolution. PeerJ 2014:e616. https://doi.org/10.7717/peerj.616

Heschel MS, Evankow A, Wolfson KB et al (2014) Drought response diversification in African Protea species. Int J Plant Sci 175:442-449. https://doi.org/10.1086/675573

Hodge S, Ward JL, Beale MH et al (2013) Aphid-induced accumulation of trehalose in Arabidopsis thaliana is systemic and dependent upon aphid density. Planta 237:1057-1064. https:// doi.org/10.1007/s00425-012-1826-4

Iler A, Inouye D, Hoye TT et al (2013) Maintenance of temporal synchrony between syrphid flies and floral resources despite differential phenological responses to climate. Glob Change Biol 19:2348-2359. https://doi.org/10.1111/gcb.12246

Jackman S (2017) pscl: classes and methods for R developed in the political science computational laboratory. R package version 1.5.2

Jamieson MA, Trowbridge AM, Raffa KF, Lindroth RL (2012) Consequences of climate warming and altered precipitation patterns for plant-insect and multitrophic interactions. Plant Physiol 160:1719-1727. https://doi.org/10.1104/pp.112.206524

Kearns CA (1992) Anthophilous fly distribution across an elevation gradient. Am Midl Nat 127:172. https://doi.org/10.2307/24263 32

Kennedy JS (1958) Physiological condition of the host-plant and susceptibility to aphid attack. Entomol Exp Appl 1:50-65. https:// doi.org/10.1111/j.1570-7458.1958.tb00009.x

Kharouba HM, Wolkovich EM (2020) Disconnects between ecological theory and data in phenological mismatch research. Nat Clim Change 10:406-415. https://doi.org/10.1038/s41558-020-0752-x
Korner-Nievergelt F, Roth T, von Felten S et al (2015) Bayesian data analysis in ecology using linear models with R, BUGS, and Stan. Academic Press, Elsevier, Amsterdam

Kummel M, Brown D, Bruder A (2013) How the aphids got their spots: predation drives self-organization of aphid colonies in a patchy habitat. Oikos 122:896-906. https://doi.org/10.111 1/j.1600-0706.2012.20805.x

Kuznetsova A, Brockhoff PB, Christensen RHB (2017) lmerTest package: tests in linear mixed effects models. J Stat Softw 82:1-26. https://doi.org/10.18637/jss.v082.i13

Lagos-Kutz D, Favret C, Giordano R, Voegtlin DJ (2016) The status of the members of the Aphis asclepiadis species group (Hemiptera: Aphididae) in the United States of America. Ann Entomol Soc Am 109:585-594. https://doi.org/10.1093/aesa/saw020

Leather SR (2018) "Ecological Armageddon"-more evidence for the drastic decline in insect numbers. Ann Appl Biol 172:1-3. https://doi.org/10.1111/aab.12410

Lenth R (2019) emmeans: estimated marginal means, aka leastsquares means. $\mathrm{R}$ package version 1.4.2

Leroy PD, Wathelet B, Sabri A et al (2011) Aphid-host plant interactions: does aphid honeydew exactly reflect the host plant amino acid composition? Arthropod Plant Interact 5:193-199. https:// doi.org/10.1007/s11829-011-9128-5

Lohaus G, Moellers C (2000) Phloem transport of amino acids in two Brassica napus L. genotypes and one B. carinata genotype in relation to their seed protein content. Planta 211:833-840

Losey JE, Denno RF (1998) The escape response of pea aphids to foliar-foraging predators: factors affecting dropping behaviour. Ecol Entomol 23:53-61. https://doi.org/10.104 6/j.1365-2311.1998.00102.x

Mooney KA, Agrawal AA (2008) Plant genotype shapes antaphid interactions: implications for community structure and indirect plant defense. Am Nat 171:E195-E205. https://doi. org/10.1086/587758

Mooney KA, Pratt RT, Singer MS (2012) The tri-trophic interactions hypothesis: interactive effects of host plant quality, diet breadth and natural enemies on herbivores. PLoS One 7:e34403. https ://doi.org/10.1371/journal.pone.0034403

Mooney EH, Phillips JS, Tillberg CV et al (2016) Abiotic mediation of a mutualism drives herbivore distribution. Ecol Lett 19:3744. https://doi.org/10.1111/ele.12540

Mooney E, Davidson B, Den Uyl J et al (2019) Elevated temperature alters an ant-aphid mutualism. Entomol Exp Appl 167:891-905. https://doi.org/10.1111/eea.12839

Morkunas I, Mai VC, Gabryś B (2011) Phytohormonal signaling in plant responses to aphid feeding. Acta Physiol Plant 33:2057-2073

Mound L, O'Donnell C (2017) Predation, phytophagy and character state confusion among North American species of the genus Leptothrips (Thysanoptera: Phlaeothripinae). Zootaxa 4294:301-315

Müller CB, Godfray HCJ (1999) Predators and mutualists influence the exclusion of aphid species from natural communities. Oecologia 119:120-125. https://doi.org/10.1007/s004420050767

Natural Resource Conservation Service (2019) Gunnison River Basin Time Series Monthly Snowpack Summary. https://www.wcc.nrcs. usda.gov/ftpref/states/co/charts/basinplotgrb18.gif. Accessed 6 Apr 2019

Ness J, Mooney K, Lach L (2010) Ants as mutualists. In: Lach L, Parr C, Abbott K (eds) Ant ecology. Oxford University Press, Oxford, p 432

Nguyen D, Rieu I, Mariani C, van Dam NM (2016) How plants handle multiple stresses: hormonal interactions underlying responses to abiotic stress and insect herbivory. Plant Mol Biol 91:727-740. https://doi.org/10.1007/s11103-016-0481-8 
Niittynen P, Heikkinen RK, Luoto M (2018) Snow cover is a neglected driver of Arctic biodiversity loss. Nat Clim Change 8:997-1001. https://doi.org/10.1038/s41558-018-0311-x

Penczykowski RM, Connolly BM, Barton BT (2017) Winter is changing: trophic interactions under altered snow regimes. Food Webs 13:80-91. https://doi.org/10.1016/j.fooweb.2017.02.006

Petry WK, Perry KI, Mooney KA (2012) Influence of macronutrient imbalance on native ant foraging and interspecific interactions in the field. Ecol Entomol 37:175-183. https://doi.org/10.111 1/j.1365-2311.2012.01349.x

Pringle EG, Novo A, Ableson I et al (2014) Plant-derived differences in the composition of aphid honeydew and their effects on colonies of aphid-tending ants. Ecol Evol 4:4065-4079. https://doi. org/10.1002/ece3.1277

Pritchard J, Griffiths B, Hunt EJ (2007) Can the plant-mediated impacts on aphids of elevated $\mathrm{CO}_{2}$ and drought be predicted? Glob Change Biol 13:1616-1629. https://doi.org/10.111 1/j.1365-2486.2007.01401.x

Qian SS (2017) Environmental and ecological statistics in R, 2nd edn. CRC Press, Taylor \& Francis Group, Boca Raton

Quental TB, Trigo JR, Oliveira PS (2005) Host-plant flowering status and the concentration of sugar in phloem sap: effects on an anttreehopper interaction. Eur J Entomol 102:201-208. https://doi. org/10.14411/eje.2005.032

R Foundation for Statistical Computing (2020) R: a language and environment for statistical computing. $\mathrm{R}$ version 3.6.3 (2020-02-29) — "Holding the Windsock"

Renner SS, Zohner CM (2018) Climate change and phenological mismatch in trophic interactions among plants, insects, and vertebrates. Annu Rev Ecol Evol Syst 49:165-182. https://doi. org/10.1146/annurev-ecolsys-110617-062535

Robinson A, Inouye DW, Ogilvie JE, Mooney EH (2017) Multitrophic interactions mediate the effects of climate change on herbivore abundance. Oecologia 185:181-190. https://doi.org/10.1007/ s00442-017-3934-0

Rumpf SB, Semenchuk PR, Dullinger S, Cooper EJ (2014) Idiosyncratic responses of high arctic plants to changing snow regimes. PLoS One. https://doi.org/10.1371/journal.pone.0086281

Sakata H (1994) How an ant decides to prey on or to attend aphids. Res Popul Ecol (Kyoto) 36:45-51. https://doi.org/10.1007/BF025 15084

Sakata H (1999) Indirect interactions between two aphid species in relation to ant attendance. Ecol Res 14:329-340. https://doi.org/ 10.1046/j.1440-1703.1999.00312.x

Sandström J (2000) Nutritional quality of phloem sap in relation to host plant-alternation in the bird cherry-oat aphid. Chemoecology 10:17-24. https://doi.org/10.1007/s000490050003

Sevanto S (2014) Phloem transport and drought. J Exp Bot 65:17511759. https://doi.org/10.1093/jxb/ert467

Stadler B, Dixon AF (1998) Costs of ant attendance for aphids. J Anim Ecol 67:454-459. https://doi.org/10.104 6/j.1365-2656.1998.00209.x
Stadler B, Dixon AF (2005) Ecology and evolution of aphid-ant interactions. Annu Rev Ecol Evol Syst 36:345-372. https://doi. org/10.1146/annurev.ecolsys.36.091704.175531

Stadler B, Dixon AF, Kindlmann P (2002) Relative fitness of aphids: effects of plant quality and ants. Ecol Lett 5:216-222. https://doi. org/10.1046/j.1461-0248.2002.00300.x

Tariq M, Wright DJ, Rossiter JT, Staley JT (2012) Aphids in a changing world: testing the plant stress, plant vigour and pulsed stress hypotheses. Agric For Entomol 14:177-185. https://doi.org/10.1 111/j.1461-9563.2011.00557.x

Thakur B, Kalra A, Lakshmi V et al (2020) Linkage between ENSO phases and western US snow water equivalent. Atmos Res 236:104827. https://doi.org/10.1016/j.atmosres.2019.104827

Vantaux A, Schillewaert S, Parmentier T et al (2015) The cost of ant attendance and melezitose secretion in the black bean aphid Aphis fabae. Ecol Entomol 40:511-517. https://doi.org/10.1111/ een. 12217

Venables WN, Ripley BD (2002) Modern applied statistics with S, 4th edn. Springer New York, New York

Völkl W, Woodring J, Fischer M et al (1999) Ant-aphid mutualisms: the impact of honeydew production and honeydew sugar composition on ant preferences. Oecologia 118:483-491. https://doi. org/10.1007/s004420050751

Weber WA, Wittmann RC (2001) Colorado flora: western slope, 3rd edn. University Press of Colorado, Boulder, p 608

White TCR (2015) Senescence-feeders: a new trophic sub-guild of insect herbivores. J Appl Entomol 139:11-22. https://doi. org/10.1111/jen.12147

Wipf S, Rixen C (2010) A review of snow manipulation experiments in Arctic and alpine tundra ecosystems. Polar Res 29:95-109. https ://doi.org/10.1111/j.1751-8369.2010.00153.x

Yao I (2014) Costs and constraints in aphid-ant mutualism. Ecol Res 29:383-391. https://doi.org/10.1007/s11284-014-1151-4

Yao I, Akimoto SI (2001) Ant attendance changes the sugar composition of the honeydew of the drepanosiphid aphid Tuberculatus quercicola. Oecologia 128:36-43. https://doi.org/10.1007/s0044 20100633

Zeileis A, Kleiber C, Jackman S (2008) Regression models for count data in R. J Stat Softw 27:1-25. https://doi.org/10.18637/jss.v027. i08

Zhang H, Zhou C (2013) Signal transduction in leaf senescence. Plant Mol Biol 82:539-545. https://doi.org/10.1007/s11103-012-9980-4

Zhu H, Wang D, Wang L et al (2014) Effects of altered precipitation on insect community composition and structure in a meadow steppe. Ecol Entomol 39:453-461. https://doi.org/10.1111/een.12120

Publisher's Note Springer Nature remains neutral with regard to jurisdictional claims in published maps and institutional affiliations. 